\title{
Frightening Music Triggers Rapid Changes in Brain Monoamine Receptors: A Pilot PET Study
}

\author{
Ying Zhang*1-4, Qiaozhen Chen*1,5, Fenglei ${ }^{1}{ }^{1}$, Yanni $\mathrm{Hu}^{1-4}$, Fangfang $\mathrm{Chao}^{1-4}$, Mei Tian $^{1-4}$, and Hong Zhang ${ }^{1-4}$ \\ ${ }^{1}$ Department of Nuclear Medicine, Second Affiliated Hospital of Zhejiang University School of Medicine, Hangzhou, China; \\ ${ }^{2}$ Zhejiang University Medical PET Center, Hangzhou, China; ${ }^{3}$ Institute of Nuclear Medicine and Molecular Imaging, Zhejiang \\ University, Hangzhou, China; ${ }^{4}$ Key Laboratory of Medical Molecular Imaging of Zhejiang Province, Hangzhou, China; and \\ ${ }^{5}$ Department of Psychiatry, Second Affiliated Hospital of Zhejiang University School of Medicine, Hangzhou, China
}

Frightening music can rapidly arouse emotions in listeners that mimic those from actual life-threatening experiences. However, studies of the underlying mechanism for perceiving danger created by music are limited. Methods: We investigated monoamine receptor changes induced by frightening music using ${ }^{11} \mathrm{C}-\mathrm{N}$-methyl-spiperone ( $\left.{ }^{11} \mathrm{C}-\mathrm{NMSP}\right) \mathrm{PET}$. Ten healthy male volunteers were included, and their psychophysiologic changes were evaluated. Results: Compared with the baseline condition, listening to frightening music caused a significant decrease in ${ }^{11} \mathrm{C}-\mathrm{NMSP}$ in the right and left caudate nuclei, right limbic region, and right paralimbic region; a particularly significant decrease in the right anterior cingulate cortex; but an increase in the right frontal occipital and left temporal lobes of the cerebral cortex. Conclusion: Transient fright triggers rapid changes in monoamine receptors, which decrease in the limbic and paralimbic regions but increase in the cerebral cortex.

Key Words: position emission tomography (PET); monoamine; receptor; music; fear

J Nucl Med 2012; 53:1573-1578

DOI: 10.2967/jnumed.112.106690

\section{$\mathbf{M}$} usic, as a tool to convey emotion and modulate mood, can evoke powerful responses. Unlike many other stimuli, music can often evoke emotion spontaneously, in the absence of external associations (1). While listening to music, individuals experience both physiologic reactions and psychologic spontaneous responses extremely rapidly and automatically (2).

Frightening music is effective at inducing fear, which can rapidly arouse emotions that mimic those from actual lifethreatening experiences. Those violent feelings of fear can

\footnotetext{
Received Mar. 28, 2012; revision accepted May 18, 2012.

For correspondence or reprints contact either of the following: Hong Zhang, Department of Nuclear Medicine, Second Affiliated Hospital of Zhejiang University, 88 Jiefang Rd., Hangzhou, Zhejiang 310009, China. E-mail: hzhang21@gmail.com

Mei Tian, Department of Nuclear Medicine, Second Affiliated Hospital of Zhejiang University, 88 Jiefang Rd., Hangzhou, Zhejiang 310009, China.

E-mail: meitian@gmail.com

${ }^{*}$ Contributed equally to this work.

Published online Aug. 29, 2012.

COPYRIGHT @ 2012 by the Society of Nuclear Medicine and Molecular Imaging, Inc.
}

arouse deeply memorable impressions and even create psychologic trauma, which may contribute to anxiety disorders. Previous functional imaging studies based on cerebral blood flow changes indicated that the emotional response to music occurs in a network of limbic and paralimbic structures $(1,3)$, and both dopamine $(4,5)$ and serotonin neural pathways (6) are involved in the modulation of fear and anxiety.

Few data are available concerning synaptic changes during music listening. A recent study by Salimpoor et al. (7) using ${ }^{11} \mathrm{C}$-raclopride PET combined with functional MRI found that endogenous dopamine is released in the striatum at peak emotional responses to pleasant music. Because the binding of ${ }^{11} \mathrm{C}$-raclopride to the dopamine receptor $2\left(D_{2}\right)$ in the striatum is reversible in the time frame of a PET scan and competitive with that of endogenous dopamine, such binding cannot reflect actual changes in postsynaptic receptor level. In contrast, ${ }^{11} \mathrm{C}-\mathrm{N}$-methylspiperone ( $\left.{ }^{11} \mathrm{C}-\mathrm{NMSP}\right)$, as a $\mathrm{D}_{2}$ and 5-hydroxytryptamine receptor $2 \mathrm{~A}\left(5-\mathrm{HT}_{2 \mathrm{~A}}\right)$ antagonist, binds the receptors substantially irreversibly in the time frame of a PET scan and was originally used to detect dopamine receptor densities in the basal ganglia (8). Since ${ }^{11} \mathrm{C}-\mathrm{NMSP}$ is not competitive with endogenous dopamine $(9,10)$ and serotonin $(11)$, binding of ${ }^{11} \mathrm{C}$-NMSP can directly reflect a postsynaptic monoamine receptor level more accurately than can binding of ${ }^{11} \mathrm{C}$-raclopride. Moreover, because ${ }^{11} \mathrm{C}-\mathrm{NMSP}$ binds predominantly to $\mathrm{D}_{2}$ in the striatum and to $5-\mathrm{HT}_{2 \mathrm{~A}}$ in the cortex, ${ }^{11} \mathrm{C}$-NMSP could also be used to map both of these receptors simultaneously in the same individual $(12,13)$.

Until now, studies on the underlying mechanism for music-evoked perception of danger have been limited. We hypothesized that the emotional processing of fear is mediated by $\mathrm{D}_{2}$ and $5-\mathrm{HT}_{2 \mathrm{~A}}$; thus, substantial differences in ${ }^{11} \mathrm{C}$-NMSP binding would be found between baseline (or resting) and music-listening conditions. To our knowledge, this is the first demonstration of acute changes of monoamine receptors in response to frightening music. In this study, ${ }^{11} \mathrm{C}-\mathrm{NMSP}$ binding both at baseline and during frightening music was evaluated in the same subjects. Realtime physical and emotional conditions were evaluated during frightening music to ensure that the music evoked a response by the listeners. 


\section{MATERIALS AND METHODS}

\section{Subjects}

Ten healthy male volunteers, with a mean age of 21.8 y (age range, 20-25 y), were recruited from students at Zhejiang University. Volunteers were selected after a complete medical screening to exclude current or past neurologic, psychiatric, or auditory disease. All subjects had no history of allergies, chronic illness, or substance addiction. All were right-handed and had no formal training in music. Written informed consent was obtained from each participant. The study was approved by the Ethic Committee of the Second Affiliated Hospital of Zhejiang University School of Medicine.

\section{Study Protocol}

A prospective, randomized, crossover pilot study was performed to compare the baseline and music-listening conditions. All volunteers successively underwent two ${ }^{11} \mathrm{C}-\mathrm{NMSP}$ PET scans on separate days (with a 3- to 10-d interval between the scans) under either the baseline condition (resting without auditory stimuli) or the music-listening condition. The procedures were explained to each subject before the initiation of the PET study in order to avoid subject anxiety during the PET scan.

During the baseline condition, the subjects were instructed to rest on the bed quietly and not move during the scan. During the music-listening condition, the subjects were instructed to lie on the bed and listen to the music attentively. A musical stimulus was selected from the Japanese horror film $\mathrm{Ju}$-On, which is widely accepted as one of the scariest and most influential movies ever made (14). Musical stimuli were presented at a stable volume by a loudspeaker. The music began $30 \mathrm{~min}$ before the ${ }^{11} \mathrm{C}$-NMSP injection and continued throughout the PET scan.

The real-time vital signs of each subject were recorded during both baseline and music-listening conditions using a bedside patient monitor (M3046A; Philips). After the PET scan under the music-listening condition, each subject was asked to self-rate his emotional valence score using a ranking from -10 (most unpleasant) to 10 (most pleasant) and his fright intensity score using a ranking from 0 (no fright) to 10 (greatest fright) (3).

\section{Data Acquisition and Analysis}

${ }^{11} \mathrm{C}-\mathrm{NMSP}$ was synthesized by an automated system (C-11-B II ${ }^{11} \mathrm{C}$-methyl iodide; Sumitomo Heavy Industries). The PET scans were obtained using a SHR-22000 camera (Hamamatsu Photonics). Dynamic PET scans were acquired at 0-60 min after intravenous injection of ${ }^{11} \mathrm{C}-\mathrm{NMSP}(740 \mathrm{MBq})$. The sequences consisted of 24 frames: $6 \times 10 \mathrm{~s}, 4 \times 30 \mathrm{~s}, 7 \times 1 \mathrm{~min}, 4 \times$ $5 \mathrm{~min}$, and $3 \times 10 \mathrm{~min}$. The PET images between 31 and $40 \mathrm{~min}$, which demonstrated higher radioactive accumulation in the brain, were selected for the image analysis.

Statistical parametric mapping analysis was performed using SPM2 (Wellcome Department of Cognitive Neurology). The threshold was set at a $P$ value of less than 0.01 , with a minimum cluster size of 100 contiguous voxels. The brain areas with increased or decreased ${ }^{11} \mathrm{C}$-NMSP binding were detected using 2 different contrasts $(1-1 ;-11)$.

\section{RESULTS}

When the music-listening condition was compared with the baseline condition, statistical parametric mapping analysis revealed significant decreases in ${ }^{11} \mathrm{C}$-NMSP bind- ing in 4 clusters (Fig. 1; Table 1). In the most significantly decreased cluster $\left(P_{\text {corrected }}=0.014 ; P_{\text {uncorrected }}<0.001\right.$; expected number of voxels per cluster $\left[\mathrm{K}_{\mathrm{E}}\right]=420$ ), 3 brain regions - the right caudate head, right frontal subgyral region, and right anterior cingulate region-were involved $(\mathrm{t}$ value $=6.04,4.09$, and 3.76, respectively) $($ Table $1 ;$ Fig. 1). In the second cluster $\left(P_{\text {corrected }}=0.091, P_{\text {uncorrected }}=\right.$ $\left.0.001, K_{\mathrm{E}}=294\right), 2$ brain regions were involved-the left lateral globus pallidus and left caudate body ( $\mathrm{t}$ value $=6.60$ and 3.76). One region, the right anterior cingulate region ( $\mathrm{t}$ value $=5.18$ and 4.82 , respectively), comprised the third cluster $\left(P_{\text {corrected }}=0.762, P_{\text {uncorrected }}=0.011, \mathrm{~K}_{\mathrm{E}}=145\right)$. In the fourth cluster $\left(P_{\text {corrected }}=0.776, P_{\text {uncorrected }}=0.012\right.$, $\mathrm{K}_{\mathrm{E}}=143$, respectively), 3 brain regions were involved-the right superior temporal gyrus, right claustrum, and right amygdala ( $\mathrm{t}$ value $=4.36,3.81$, and 3.61, respectively).

The ${ }^{11} \mathrm{C}-\mathrm{NMSP}$ accumulation significantly increased in 4 clusters $\left(P_{\text {corrected }}>0.05, P_{\text {uncorrected }}<0.01\right)$ (Table 2; Fig. 2). The right frontal lobe and middle frontal gyrus comprised the first cluster ( $\mathrm{t}$ value $=4.05, P_{\text {corrected }}=0.292, P_{\text {uncorrected }}$ $\left.=0.003, \mathrm{~K}_{\mathrm{E}}=219\right)$. In the second cluster $\left(P_{\text {corrected }}=\right.$ $0.517, P_{\text {uncorrected }}=0.006, \mathrm{~K}_{\mathrm{E}}=179$ ), 2 brain regions were involved - the right fusiform gyrus and right middle occipital gyrus ( $\mathrm{t}$ value $=6.19$ and 3.76, respectively). In the third cluster $\left(P_{\text {corrected }}=0.719, P_{\text {uncorrected }}=0.01, \mathrm{~K}_{\mathrm{E}}=\right.$ 151), 3 brain regions were involved - the right superior occipital gyrus, right middle occipital gyrus, and superior occipital gyrus (t value $=4.46,4.37$, and 4.02 , respectively). The left middle temporal gyrus comprised the fourth cluster $\left(\mathrm{t}\right.$ value $=6$ and $3.76, P_{\text {corrected }}=0.842$, $P_{\text {uncorrected }}=0.014, \mathrm{~K}_{\mathrm{E}}=133$ ).

The change in heart rate or respiratory frequency was calculated as follows: (frightening music - baseline)/baseline $\times 100 \%$. Under the music-listening condition, heart rate and respiratory frequency increased $16.06 \%$ and $42.91 \%$, respectively. All subjects had unpleasant feelings when listening to the frightening music, with an average emotional valence score of -3.25 and a frightening intensity rate of 5 .

\section{DISCUSSION}

In the present study, the physiologic (heart rate and respiratory frequency) changes and self-rated emotional scores confirmed that the frightening music can evoke fear consistently. When music-listening and baseline conditions were compared, ${ }^{11} \mathrm{C}$-NMSP PET revealed that fear triggered rapid monoamine receptor changes. To the best of our knowledge, this is the first ${ }^{11} \mathrm{C}$-NMSP PET study of postsynaptic monoamine receptor changes in healthy volunteers during the music-listening condition.

Previous studies found that responses to music are related to several parts of the nervous system, because auditory information passes through the limbic and paralimbic systems $(1,3)$-including the thalamus, hypothalamus, and amygdala - to the neocortex and influences the pituitary gland, thus inducing various physiologic effects (15). The caudate nucleus, located in the dorsal striatum, 

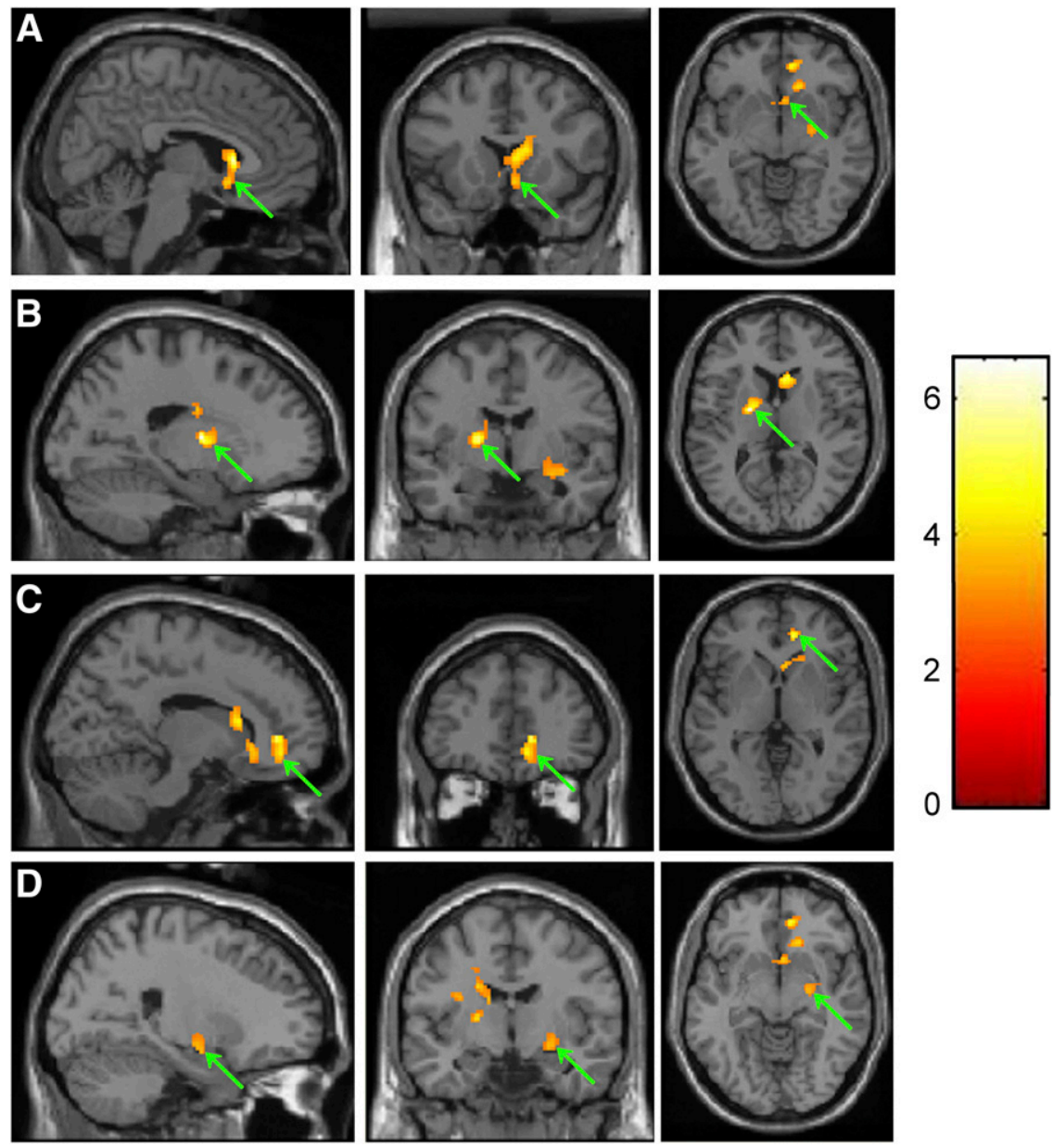

FIGURE 1. PET images showing decrease in ${ }^{11} \mathrm{C}$-NMSP binding clusters (arrows) in subject listening to frightening music: right caudate head, right frontal subgyrus, and right anterior cingulate (A); left lateral globus pallidus and left caudate body $(\mathrm{B})$; right anterior cingulate $(\mathrm{C})$; and right superior temporal gyrus, right claustrum, and right amygdala (D).

is highly involved in learning and memory (16) and has been implicated in responses to visual beauty (17). A recent study found that the caudate was more involved during the anticipatory phase and that the nucleus accumbens was more involved during the peak emotional response to pleasant music (7). In this study, we observed that ${ }^{11} \mathrm{C}-\mathrm{NMSP}$ binding significantly decreased bilaterally in the caudate nucleus in response to frightening music, indicating that the music triggers downregulation of postsynaptic $\mathrm{D}_{2}$. This result, together with results from previous studies, suggested that the caudate nucleus is involved in a wide range of emotional processes evoked by music $(7,18)$.

TABLE 1

Decreased ${ }^{11} \mathrm{C}-N M S P$ Binding During Music-Listening Condition, Compared with Baseline Condition

\begin{tabular}{|c|c|c|c|c|c|c|c|c|c|}
\hline \multirow[b]{2}{*}{ Region } & \multirow[b]{2}{*}{$\mathrm{BA}$} & \multicolumn{3}{|c|}{ Coordinate $(\mathrm{mm})$} & \multirow[b]{2}{*}{$\mathrm{t}$ value } & \multirow[b]{2}{*}{$z$ score } & \multicolumn{3}{|c|}{ Cluster level } \\
\hline & & $x$ & $y$ & $z$ & & & $P_{\text {corrected }}$ & $\mathrm{K}_{\mathrm{E}}$ & $P_{\text {uncorrected }}$ \\
\hline Right caudate head & & 6 & 18 & 5 & 6.04 & 3.73 & 0.014 & 420 & $<0.001$ \\
\hline Right frontal lobe, subgyrus & 47 & 18 & 27 & -10 & 4.09 & 3.00 & 0.014 & 420 & $<0.001$ \\
\hline Right limbic lobe, anterior cingulate & 25 & 6 & 15 & -7 & 3.76 & 2.84 & 0.014 & 420 & $<0.001$ \\
\hline Left lentiform nucleus, lateral globus pallidus & & -18 & -5 & 9 & 6.60 & 3.89 & 0.091 & 294 & 0.001 \\
\hline Left caudate body & & -14 & 1 & 17 & 3.76 & 2.84 & 0.091 & 294 & 0.001 \\
\hline Right limbic lobe, anterior cingulate & 32 & 14 & 41 & 0 & 5.18 & 3.44 & 0.762 & 145 & 0.011 \\
\hline Right limbic lobe, anterior cingulate & 32 & 12 & 42 & -9 & 4.82 & 3.31 & 0.762 & 145 & 0.011 \\
\hline Right temporal lobe, superior temporal gyrus & 38 & 38 & 3 & -14 & 4.36 & 3.12 & 0.776 & 143 & 0.012 \\
\hline Right claustrum & & 34 & -2 & -10 & 3.81 & 2.87 & 0.776 & 143 & 0.012 \\
\hline Right amygdala & & 24 & -8 & -8 & 3.61 & 2.77 & 0.776 & 143 & 0.012 \\
\hline
\end{tabular}

$\mathrm{BA}=$ Brodmann area. 
TABLE 2

Increased ${ }^{11} \mathrm{C}-\mathrm{NMSP}$ Binding During Music-Listening Condition, Compared with Baseline Condition

\begin{tabular}{|c|c|c|c|c|c|c|c|c|c|}
\hline \multirow[b]{2}{*}{ Region } & \multirow[b]{2}{*}{$\mathrm{BA}$} & \multicolumn{3}{|c|}{ Coordinates $(\mathrm{mm})$} & \multirow[b]{2}{*}{$t$ value } & \multirow[b]{2}{*}{$z$ score } & \multicolumn{3}{|c|}{ Cluster level } \\
\hline & & $x$ & $y$ & $z$ & & & $P_{\text {corrected }}$ & $\mathrm{K}_{\mathrm{E}}$ & $P_{\text {uncorrected }}$ \\
\hline Right frontal lobe, middle frontal gyrus & 9 & 36 & 31 & 30 & 4.05 & 2.98 & 0.292 & 219 & 0.003 \\
\hline Right occipital lobe, fusiform gyrus & 19 & 40 & -68 & -7 & 6.19 & 3.77 & 0.517 & 179 & 0.006 \\
\hline Right occipital lobe, middle occipital gyrus & 37 & 42 & -68 & 3 & 3.76 & 2.84 & 0.517 & 179 & 0.006 \\
\hline Right occipital lobe, superior occipital gyrus & 19 & 38 & -82 & 28 & 4.46 & 3.16 & 0.719 & 151 & 0.010 \\
\hline Right occipital lobe, middle occipital gyrus & 19 & 36 & -75 & 15 & 4.37 & 3.12 & 0.719 & 151 & 0.010 \\
\hline Right occipital lobe, superior occipital gyrus & 19 & 40 & -75 & 24 & 4.02 & 2.97 & 0.719 & 151 & 0.010 \\
\hline Left temporal lobe, middle temporal gyrus & 39 & -40 & -67 & 22 & 6.00 & 3.72 & 0.842 & 133 & 0.014 \\
\hline Left temporal lobe, middle temporal gyrus & 37 & -42 & -64 & 9 & 3.76 & 2.84 & 0.842 & 133 & 0.014 \\
\hline
\end{tabular}

Another noteworthy finding is that ${ }^{11} \mathrm{C}$-NMSP binding in the right amygdala increased significantly during frightening music. The limbic and paralimbic systems have long been considered implicated in the processing of emotions evoked by music. Particularly, the amygdala, which receives the information, determines the significance of the stimulus, and triggers emotional responses, is considered the most important structure (19). The metaanalysis of emotional processing revealed that the amygdala not only is activated during fear in healthy subjects but also is related to emotional neurocircuits in anxiety disorders, such as posttraumatic stress disorder, social anxiety disorder, and phobias (19). Interestingly, patients whose amygdala had been resected had an impaired ability to identify frightening music (20). Our data provided further evidence at the receptor level and indicated that frightening music triggers functional regulation of monoamine receptors in the amygdala.
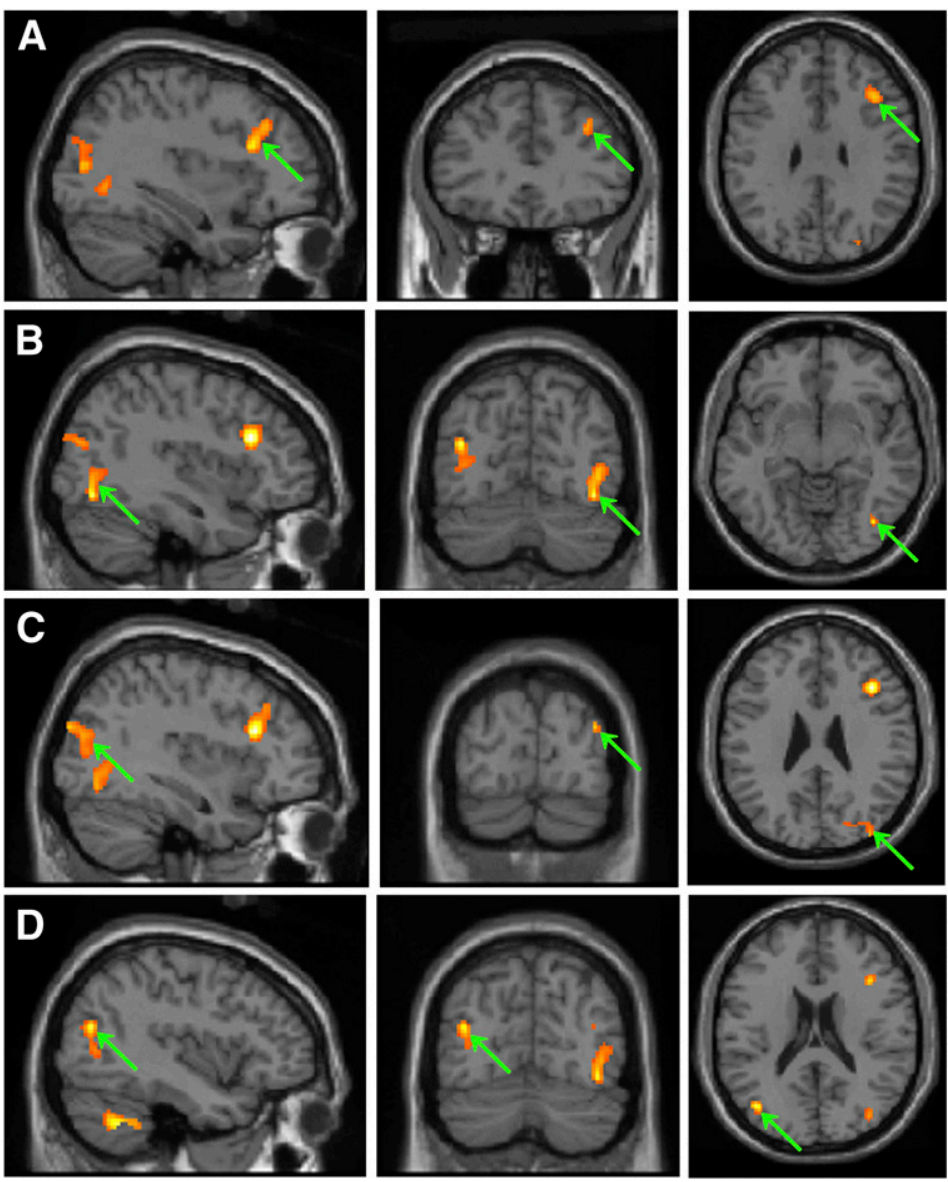

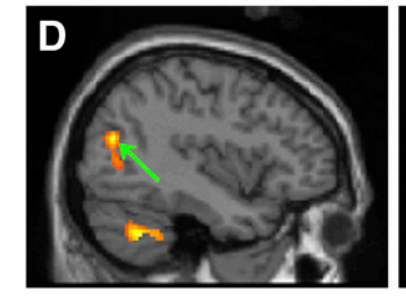

FIGURE 2. PET images showing increase in ${ }^{11} \mathrm{C}$-NMSP binding clusters (arrows) in subject listening to frightening music: right frontal lobe, and middle frontal gyrus $(A)$; right fusiform gyrus and right middle occipital gyrus $(\mathrm{B})$; right superior occipital gyrus and right middle occipital gyrus (C); and left middle temporal gyrus (D).

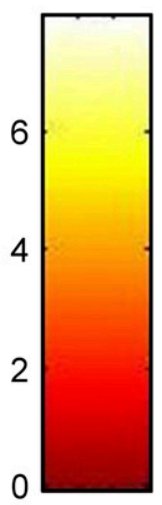


In addition to the decreased accumulation of ${ }^{11} \mathrm{C}-\mathrm{NMSP}$ in the amygdala, we also found significant increases in ${ }^{11} \mathrm{C}$ NMSP binding in the frontal, temporal, and occipital cortices when comparing the baseline condition with the music-listening condition. This finding is consistent with the classic pathway and indicated that the amygdala receives frightening-music stimuli from the limbic and paralimbic system and then sends its afferents to the cortex. In the cortex, the stimuli are analyzed using information from many parts of the brain, and a message is sent back down to the amygdala. In return, the amygdala reacts to stimuli and triggers physiologic responses. Because $5-\mathrm{HT}_{2 \mathrm{~A}}$ density is significantly higher than the density of $\mathrm{D}_{2}$ in the cerebral cortex $(12,13)$, we assume that changes in ${ }^{11} \mathrm{C}$ NMSP binding mainly reflect $5-\mathrm{HT}_{2 \mathrm{~A}}$ levels in the cortex. Interestingly, in the present study, greater changes in ${ }^{11} \mathrm{C}$ NMSP binding were found on the right side of the frontal, temporal, and occipital cortices and of the amygdala. A previous study using electroencephalography and functional MRI reported that listening to frightening or sad music increases the activity of the right frontal cortex whereas listening to pleasurable music increases the activity of the left frontal cortex (21). These increases are due to the different functional divisions in the 2 sides of the cerebral cortex. The asymmetry pattern may be considered to indicate the superiority of the right hemisphere for the processing of auditory stimuli and the defense reaction to fear. These findings will help us learn the mechanism by which the brain responds to fear and gain a better understanding of anxiety disorders.

Our study suggests that the receptor modification response to fear covers multiple brain regions related to the cortical-limbic loop. However, the mechanisms underlying rapid changes in the apparent densities of the postsynaptic receptors need to be investigated in future studies. It is known that $\mathrm{D}_{2}$ and 5- $\mathrm{HT}_{2 \mathrm{~A}}$ are the most important molecules in this process, and both are stimulatory G-proteincoupled receptors. Because the synthesis of membrane receptor proteins requires time, the mechanism for instant receptor down- or upregulation may be achieved by a phosphorylation or dephosphorylation event involving receptor protein, which activates a sequence of biochemical cascades in most cases (22). Some of these rapid changes may occur through neural interaction, such as glutamatergicdopaminergic or cholinergic-serotonergic interaction, because the brain manifests various functions by means of complex interactions among multiple neurotransmitters (22-24). Additionally, rapid receptor internalization or membrane fluidity might contribute to the temporarily restored intracellular receptor protein expressed on the cell membrane (25).

Although the current study has the advantage of determining the changes in 2 monoamine receptors directly and simultaneously, some limitations should be addressed in future studies. For example, ${ }^{11} \mathrm{C}-\mathrm{NMSP}$ PET was performed during a short period in this present study, and only a transient change in monoamine receptor could be revealed. To get more information on the effect of frightening music, a long-term, repetitive PET study should be conducted. In addition, music of different types and intensities should be tested in the future studies. Furthermore, because PET does not afford the temporal resolution required to identify overlapping region in the clusters, a combined imaging technology such as PET/MRI may be useful.

\section{CONCLUSION}

Transient fright was found to trigger rapid changes in monoamine receptors, which decreased in the limbic and paralimbic regions but increased in the cerebral cortex. This ${ }^{11} \mathrm{C}$-NMSP PET study found the right hemisphere to have superiority in the processing of auditory stimuli and the defense reaction.

\section{DISCLOSURE STATEMENT}

The costs of publication of this article were defrayed in part by the payment of page charges. Therefore, and solely to indicate this fact, this article is hereby marked "advertisement" in accordance with 18 USC section 1734.

\section{ACKNOWLEDGMENTS}

We thank Prof. Robert Freedman, Department of Psychiatry of the University of Colorado Health Sciences Center, for helpful comments on the manuscript. This work was partly sponsored by grants from the Zhejiang Provincial Natural Science Foundation of China (Z2110230), Health Bureau of Zhejiang Province (2010ZA075 and 2011ZDA013), National Science Foundation of China (NSFC) (nos. 81101023, 81271601, and 81173468), Ministry of Science and Technology of China (2011CB504400), and National Science Technology Support Program (2012BAI13B06). No other potential conflict of interest relevant to this article was reported.

\section{REFERENCES}

1. Blood AJ, Zatorre RJ, Bermudez P, Evans AC. Emotional responses to pleasant and unpleasant music correlate with activity in paralimbic brain regions. Nat Neurosci. 1999;2:382-387.

2. Bigand E, Filipic S, Lalitte P. The time course of emotional responses to music. Ann N Y Acad Sci. 2005;1060:429-437.

3. Koelsch S, Fritz T, DY VC, Muller K, Friederici AD. Investigating emotion with music: an fMRI study. Hum Brain Mapp. 2006;27:239-250.

4. de la Mora MP, Gallegos-Cari A, Arizmendi-Garcia Y, Marcellino D, Fuxe K. Role of dopamine receptor mechanisms in the amygdaloid modulation of fear and anxiety: structural and functional analysis. Prog Neurobiol. 2010;90:198216.

5. Schneier FR, Liebowitz MR, Abi-Dargham A, Zea-Ponce Y, Lin SH, Laruelle M. Low dopamine $\mathrm{D}(2)$ receptor binding potential in social phobia. Am J Psychiatry. 2000; 157:457-459.

6. Zanoveli JM, Carvalho MC, Cunha JM, Brandao ML. Extracellular serotonin level in the basolateral nucleus of the amygdala and dorsal periaqueductal gray under unconditioned and conditioned fear states: an in vivo microdialysis study. Brain Res. 2009;1294:106-115.

7. Salimpoor VN, Benovoy M, Larcher K, Dagher A, Zatorre RJ. Anatomically distinct dopamine release during anticipation and experience of peak emotion to music. Nat Neurosci. 2011;14:257-262.

8. Wagner HN Jr, Burns HD, Dannals RF, et al. Imaging dopamine receptors in the human brain by positron tomography. Science. 1983;221:1264-1266. 
9. Morris ED, Yoder KK. Positron emission tomography displacement sensitivity: predicting binding potential change for positron emission tomography tracers based on their kinetic characteristics. J Cereb Blood Flow Metab. 2007;27:606-617.

10. Ishibashi K, Ishii K, Oda K, Mizusawa H, Ishiwata K. Competition between ${ }^{11} \mathrm{C}$-raclopride and endogenous dopamine in Parkinson's disease. Nucl Med Commun. 2010;31:159-166.

11. Paterson LM, Tyacke RJ, Nutt DJ, Knudsen GM. Measuring endogenous 5-HT release by emission tomography: promises and pitfalls. J Cereb Blood Flow Metab. 2010;30:1682-1706.

12. Nyberg S, Eriksson B, Oxenstierna G, Halldin C, Farde L. Suggested minimal effective dose of risperidone based on PET-measured D2 and 5-HT2A receptor occupancy in schizophrenic patients. Am J Psychiatry. 1999;156:869-875.

13. Gefvert O, Lundberg T, Wieselgren IM, et al. D(2) and 5HT(2A) receptor occupancy of different doses of quetiapine in schizophrenia: a PET study. Eur Neuropsychopharmacol. 2001;11:105-110.

14. Shimizu T. Ju-On [DVD]. Santa Monica, CA: Lionsgate Entertainment Corp.; 2004.

15. Fukui H, Toyoshima K. Music facilitate the neurogenesis, regeneration and repair of neurons. Med Hypotheses. 2008;71:765-769.

16. Karabanov A, Cervenka S, de Manzano O, Forssberg H, Farde L, Ullen F. Dopamine D2 receptor density in the limbic striatum is related to implicit but not explicit movement sequence learning. Proc Natl Acad Sci USA. 2010;107:7574-7579.
17. Ishizu T, Zeki S. Toward a brain-based theory of beauty. PLoS ONE. 2011;6: e21852.

18. Bressan RA, Crippa JA. The role of dopamine in reward and pleasure behaviour: review of data from preclinical research. Acta Psychiatr Scand Suppl. 2005; 427:14-21.

19. Etkin A, Wager TD. Functional neuroimaging of anxiety: a meta-analysis of emotional processing in PTSD, social anxiety disorder, and specific phobia. Am J Psychiatry. 2007;164:1476-1488.

20. Gosselin N, Peretz I, Noulhiane M, et al. Impaired recognition of scary music following unilateral temporal lobe excision. Brain. 2005;128:628-640.

21. Flores-Gutiérrez EO, Diaz JL, Barrios FA, et al. Metabolic and electric brain patterns during pleasant and unpleasant emotions induced by music masterpieces. Int J Psychophysiol. 2007;65:69-84.

22. Pierce KL, Premont RT, Lefkowitz RJ. Seven-transmembrane receptors. Nat Rev Mol Cell Biol. 2002;3:639-650.

23. Mora F, Segovia G, Del Arco A. Glutamate-dopamine-GABA interactions in the aging basal ganglia. Brain Res Rev. 2008;58:340-353.

24. Steckler T, Sahgal A. The role of serotonergic-cholinergic interactions in the mediation of cognitive behaviour. Behav Brain Res. 1995;67:165-199.

25. Goggi JL, Sardini A, Egerton A, Strange PG, Grasby PM. Agonist-dependent internalization of D2 receptors: Imaging quantification by confocal microscopy. Synapse. 2007;61:231-241. 